\title{
Pemasangan DGR (Directional Ground Relay) untuk Mengatasi Gangguan Sympathetic Trip pada GIS Bandara Penyulang Ngurah Rai I dan Ngurah Rai II
}

\author{
I Nyoman Upanayana ${ }^{1}$, I Gede Dyana Arjana $^{2}$, I Wayan Arta Wijaya ${ }^{3}$
}

\begin{abstract}
The fault one phase to ground can make interference with sympathetic trip which cause zero sequence in phase of the fault. For feeder has a parallel network system such as feeder at Ngurah Rai I and Ngurah Rai II was very susceptible to interference between feeder sympathetic trip, because relay GFR (Ground Fault Relay) on the feeder Ngurah Rai I dan Ngurah Rai II can not secure the fault, then to resolve the sympathetic trip at the feeder Ngurah Rai I dan Ngurah Rai II was installed relay DGR (Directional Ground Relay) to prevent fault and system reliability feeder Ngurah Rai I and Ngurah Rai II turn on. Analisis the relay DGR to handle the fault sympathetic trip got value for setting relay is $I_{\text {set }}=9.334 \mathrm{~A}$, SI, time trip current fault $t=0.297$, $Z C T=1 A, G P T=34,64 k V$. So to resolve the sympathetic trip, installation relay DGR is necessary if the system network or feeder operating in loop and adjacent each in one bus.
\end{abstract}

Intisari-Gangguan 1 fasa ke tanah dapat menyebabkan terjadinya gangguan sympathetic trip yang menimbulkan arus urutan nol (arus residu) pada fasa yang terganggu. Penyulang yang memiliki sistem jaringan paralel seperti penyulang Ngurah Rai I dan Ngurah Rai II sangat rentan terjadinya gangguan sympathetic trip, karena relay GFR (Ground Fault Relay) pada penyulang Ngurah Rai I dan Ngurah Rai II tidak bisa mengamankan gangguan tersebut, maka untuk mengatasi gangguan sympathetic trip pada penyulang Ngurah Rai I dan Ngurah Rai II pemasangan relay DGR (Directional Ground Relay) akan mencegah terjadinya gangguan tersebut, dan sistem keandalan penyulang Ngurah Rai I dan Ngurah Rai II tetap terjaga. Hasil analisis perhitungan relay DGR untuk menangani gangguan sympathetic trip didapatkan besar nilai setting relay yaitu $I_{\text {set }}=9.334 \mathrm{~A}, S I$, Waktu trip Arus gangguan $\mathrm{t}=\mathbf{0 . 2 9 7}$, $Z C T=1 \mathrm{~A}, G P T=34.64 \mathrm{kV}$. Jadi untuk mengatasi gangguan sympathetic trip, relay $D G R$ sangat diperlukan jika jaringan atau penyulang beroprasi secara loop dan letaknya berdekatan satu bus.

Kata Kunci: Sympathetic trip, Setting GFR, Setting DGR, Gangguan 1 fasa ketanah

\section{Pendahuluan}

Energi listrik sangat penting bagi masyarkat bahkan energi listrik sebagai kebutuhan sehari hari bagi masyarakat Indonesia. Bali selatan adalah pusat pariwisata di pulau Bali, penggunaan listrik terpadat di Bali selatan dikarenakan terdapat banyak hotel, villa dan tempat hiburan lainnya.

${ }^{1}$ Mahasiswa Jurusan Teknik Elektro dan Komputer Fakultas Teknik Universitas Udayana Jln. Kampus Bukit Jimbaran 80361 INDONESIA (telp: 0361-703315; fax: 0361-4321: e-mail: upanayana@yahoo.co.id

Dosen ,Jurusan Teknik Elektro dan Komputer Fakultas Teknik Universitas Udayana, Jln. Jalan Kampus Bukit Jimbaran 80361 INDONESIA (telp: 0361-703315; fax: 0361-4321; e-mail: Idyanaarjana@ee.unud.ac.id, ${ }^{2}$ artawijaya@ee.unud.ac.id
Mendistribusikan energi listrik pada daerah padat tentu saja akan mengalai banyak gangguan, salah satu gangguan pada penyulang $20 \mathrm{kV}$ yaitu gangguan hubung singkat 1 fasa ke tanah yang dapat menyebabkan terjadinya sympathetic trip pada penyulang dengan bentuk paralel dan satu bus dengan penyulang lainya, seperti pada peyulang Ngurah Rai I dan Ngurah Rai II yang berbentuk paralel, dimana penyulang Ngurah Rai I dan Ngurah Rai II yang menyuplai daya listrik ke beban Bandara II sebesar $10.380 \mathrm{kVA}$, panjang kabel penyulang Ngurah Rai I dan Ngurah Rai II adalah 4,242 kms (kilometer sirkuit).

Relay merupakan peralatan pengaman yang digunakan untuk mendeteksi adanya gangguan pada setiap system jaringan listrik atau pada penyulang [1]. Untuk penyulang Ngurah Rai I dan Ngurah Rai II yang menyuplai beban VVIP diharapkan tidak pernah terjadi gangguan sympathetic trip, agar tidak terjadi gangguan sympathetic trip, maka pemasangan relay yang selektif untuk mendeteksi gangguan dan menjagan system keandalan pada penyulang sangat diperlukan. DGR (Directional Ground Relay) adalah relay arah yang bekerja berdasarkan jika mendeteksi sudut fasa yang timbul dari ketidak simbangan tegangan dan arus pada saat gangguan hubung singkat 1 fasa ketanah, tegangan urutan nol dan arus urutan nol [2].

Pada penelitian ini membahas pemasangan relay DGR untuk mengatasi gangguan sympathetic trip yang rentan terjadinya pada penyulang parallel seperti pada penyulang Ngurah Rai I dan Ngurah Rai II terlebih dahulu menentukan gangguan 1 fasa ketanah dengan perhitungan dan menentukan nilai setting relay $D G R$ untuk mengatasi jika terjadinya gangguan sympathetic trip pada penyulang Ngurah Rai I dan Ngurah Rai II. Agar gangguan sympathetic trip pada salah satu penyulang Ngurah Rai I dan Ngurah Rai II tidak terjadi dan kontinuitas penyulang Ngurah Rai I dan Ngurah Rai II tetap terjaga.

\section{TinjauAn PUSTAKA}

\section{A. Relay DGR (Directional Ground Relay)}

$D G R$ adalah relay gangguan tanah berarah dipasang pada penyulang $20 \mathrm{kV}$ sebagai pengaman untuk mendeteksi atau mengamankan gangguan 1 phasa ke tanah. Relay ini bekerja berdasarkan jika mendeteksi dua besaran, yaitu GPT (Ground Potential Transformer) mendeteksi tegangan urutan nol $\left(V_{0}\right)$ dan ZCT (Zero Current Transformer) mendeteksi arus urutan $\left(I_{0}\right)[3]$.

Setiting GPT memiliki tap setting 5-10 V, dimana setiap 1 volt sama dengan $4 \mathrm{kV}$ maka 5 volt sama dengan $20 \mathrm{kV}$ untuk tengan seimbang pada penyulang $20 \mathrm{kV}$. Perhitungan 
tegangan pada GPT untuk relay DGR dapat dihitung sebagai berikut [3].

$V_{R-N}=3 \times \frac{\text { Tegangan }}{\sqrt{3}}$

Sama dengan GPT, ZCT memiliki tap setting arus 1-5 A pada primer, jika terjadi gangguan 1 fasa ketanah dan menimbulkan arus urutan nol yang begitu kecil maka ZCT pada relay DGR akan mendeteksi arus urutan nol yang kembali kesumber dan dapat mebebani penyulang sehat sehingga ikut merasakan gangguan dan terjadi trip. Untuk menghindari terjadinya hal tersebut, settingan ZCT pada relay $D G R$ untuk kerja relay arus maksimum dapat dihitung sebagai berikut [3]:

$I_{\text {set }}=10 \% \times I_{\text {f minimum }}$

\section{B. Gangguan Sympathetic}

Sympathetic trip adalah kejadian terbukanya PMT dari penyulang - penyulang lain yang tidak terganggu, Gangguan ini terjadi karena adanya gangguan satu fasa ketanah, dimana kembalinya arus gangguan urtuan nol atau arus residu ke sumber melalui fasa terganggu dan membenbani penyulang sehat yang terletak berdekatan dan satu bus dengan penyulang yang tergangguan [4]

\section{Impeadansi Penyulang}

Impedansi penyulang dihitung berdasarkan panjang penyulang dan jenis kabel pada penyulang, dapat dilihat sebagai berikut [5].

$\mathrm{Z}=(\mathrm{R}+\mathrm{jX}) \Omega / \mathrm{km}$

\section{Teori Komponen Simetri}

Arus dan tegangan pada titik hubung singkat dihitung jika sistem tidak seimbang dan pada saat sistem seimbang, maka penggunaan metode simetri untuk menganalisa gangguan hubung singkat [3].

Sistem jaringan tiga fasa yang tidak seimbang karena adanya gangguan yang dapat diuraikan seperti gambar (1)

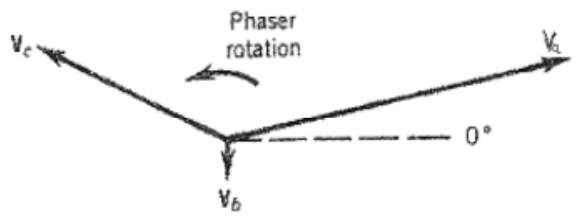

Gambar 1. Fasor Tak Simetris

Pada sistem jaringan distribusi tiga fasa, arus arus residu (Ir) dengan arus saluran sama besarnya dan kembali dengan melalui netral [3].

Arus gangguan menjadi

$I_{f}=I_{a}(p u) . I_{\text {dasar }}$

\section{E. Perhitungan Sistem Per Unit (PU)}

Pada sistem jaringan distribusi menggunakan perhitungan sistem per unit untuk mempermudah perhitungan pada sistem jaringan. Nilai asli dibagi dengan nilai dasar pada sistem jaringan sebagai berikut [3].

Nilai perunit $=\frac{\text { nilai asli }}{\text { nilai dasar }}$

Menghitung besaran nilai $I_{\text {dasar }}$ untuk sistem jaringan distribusi tiga fasa [3]

$I_{\text {dasar }}=\frac{M V A_{3 \phi} \text { dasar }}{\sqrt{3} \times \text { Tegangan dasar }, k V_{L-L}}$

dan menghitung besaran pada tahanan $Z_{\text {dasar }}$ pada sistem jaringan tiga fasa [3]

$Z_{\text {dasar }}=\frac{\left(\text { Tegangandasar }, k V_{L-L}\right)}{M V A_{3 \phi}}$

\section{F. Perhitungan Gangguan Hubung Singkat 1 Fasa ketanah}

Gangguan hubung singkat satu fasa ketanah pada jaringan distribusi mengakibatkan sistem tidak seimbang. komponen postif, negatif, dan nol adalah komponen tiga fasor yang tak seimbang [6]

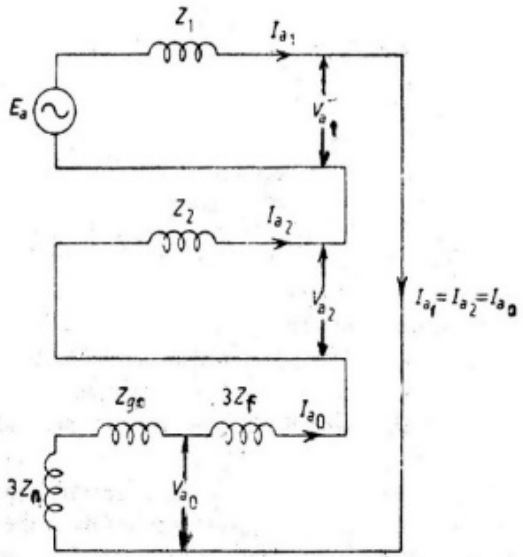

Gambar 2. Rangkaian Urutan untuk Hubung Singkat 1 Fasa ke Tanah

Perhitungan hubung singkat 1 fasa dengan fasor yang tak seimbang sebagai berikut [3]

$I a_{1}=I a_{2}=I a_{0}=\frac{E a}{\left(Z_{1}+Z_{2}+Z_{n}+3 Z_{n}+3 Z f\right)}$

\section{F. Setting Waktu (TMS)}

TMS adalah Time multiple setting digunakan untuk waktu kerja relay agar lebih sensitive [3]

$T m s=\frac{t x\left(\left(\frac{I_{f}}{I_{\text {set }}}\right)^{\alpha}\right)-1}{\beta}=S I$

sehingga

Waktu trip relay

$t=\frac{\beta \times t m s}{\left[\frac{\text { Ifault }}{\text { Iset }}\right]^{a}-1}=\operatorname{detik}$

I Nyoman Upanayana: Pemasangan DGR (Directional Ground Relay)... 


\section{METODE PENELITIAN}

Dalam penelitian ini menggunakan data - data yang mendukung pelaksanaan dari proses penelitian yang dilakukan. Data dalam pembahasan penelitian ini bersumber dari data PT. PLN (Persero) Distribusi Bali Area Jaringan Bali Selatan dan sumber - sumber lainnya. Jenis data penelitian ini mengunakan data skunder.

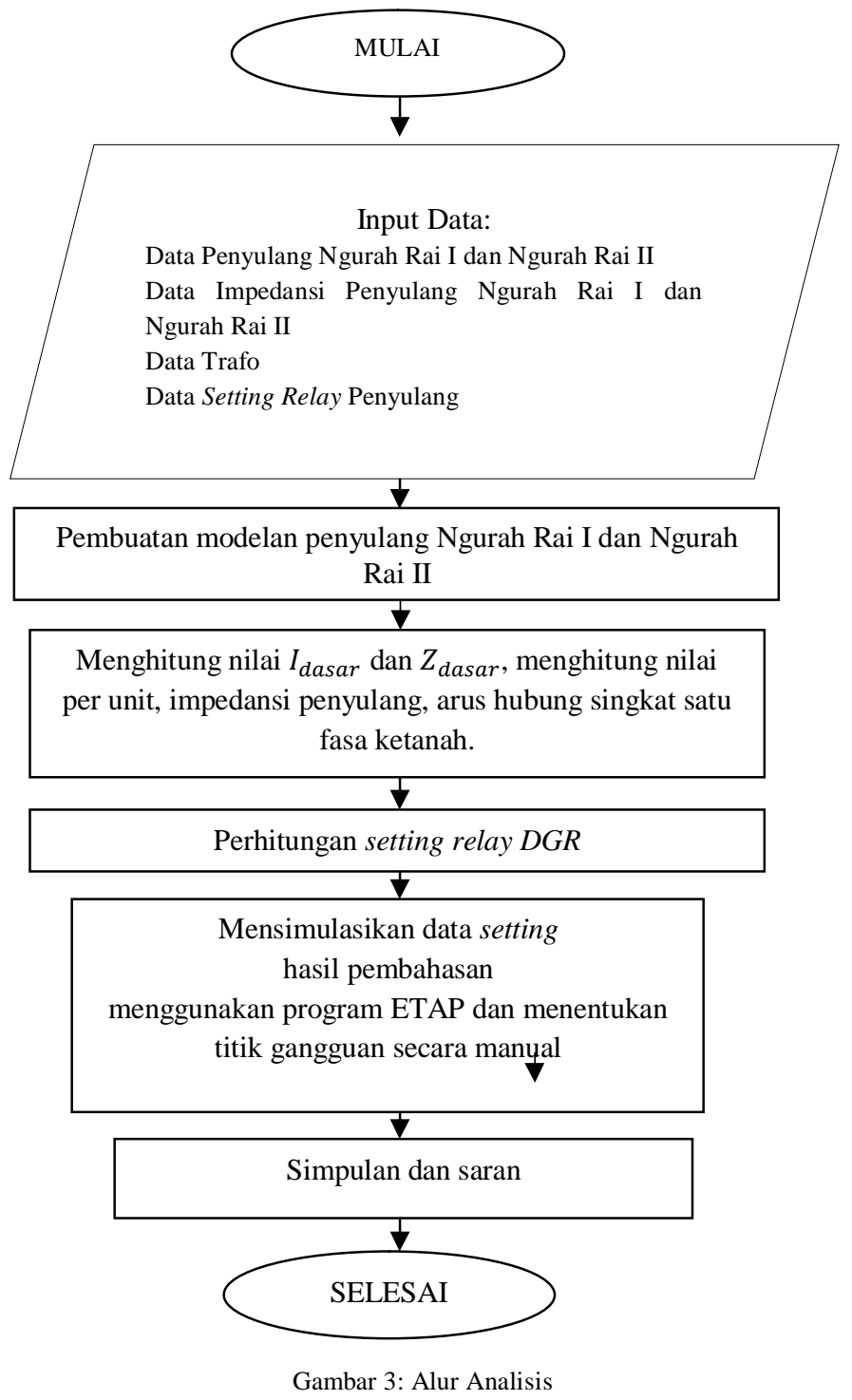

\section{A. Prosedur Penelitian}

Analisis dalam penelitian ini menggunakan data - data seperti data penyulang Ngurah Rai I dan Ngurah Rai II, data impedansi saluran penyulang Ngurah Rai I dan Ngurah Rai II, data Trafo GIS Bandara, data setting relay penyulang Ngurah Rai I dan Ngurah Rai II

Perhitungan relay $D G R$ memiliki beberapa tahap antara lain menghitung arus nominal, menghitung arus hubung singkat 1 fasa ketanh, menghitung arus setting relay dan menghitung waktu trip relay, selanjutnya mensimulasikan hasil setting relay DGR yang di peroleh dari perhtungan pada program ETAP.

\section{B. Alur Analisis Data}

Alur perhitungan analisis setting relay DGR untuk mengatasi gangguan sympathetic trip pada penyulang Ngurah Rai I dan Ngurah Rai II

\section{HASIL DAN ANALISIS}

\section{A. Single Line Diagram Penyulang Ngurah Rai I dan Ngurah} Rai II

Penyulang Ngurah Rai I dan Ngurah Rai II merupakan penyulang dengan bentuk parallel, jika terjadinya gangguan 1 fasa ketanah pada penyulang maka akan rentang terjadinya gangguan sympathetic trip.

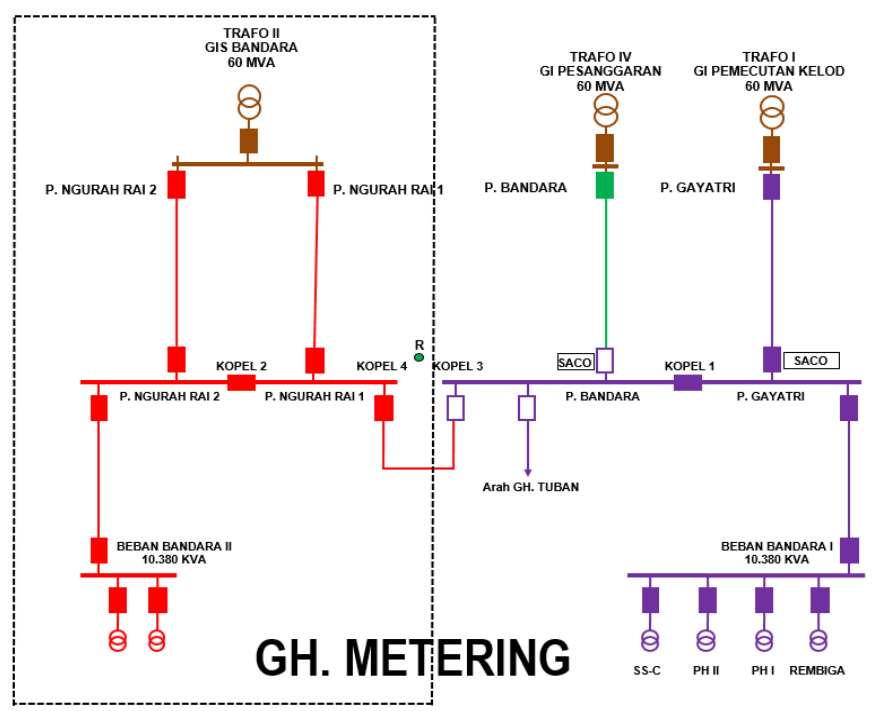

Gambar 4:. Single Line Diagram Penyulang Ngurah Rai I dan Ngurah Rai II

\section{B. Kesalahan Kordinasi Relay pada saat Gangguan 1 fasa Ketanah}

Kesalahan kordinasi di tahun 2013 saat penyulang Ngurah Rai I terkena gangguan tanah dan menyebabkan relay pada penyulang Ngurah Rai I ikut merasakan terjadinya gangguan menyebabkan tripnya kedua penyulang sehingga beban bandara dua mejadi padam.

Dari setting relay GFR yang di peroleh dari data PLN jika terjadi gangguan satu fasa ketanah pada penyulang Ngurah Rai I yang menimbulkan arus urutan nol (diasumsikan arus residu) mengalir kembali ke sumber melaui fasa yang terganggu dan kembali mengalir melalui bus, sehingga dirasakan penyulang sehat yang berada pada satu bus dengan letak penyulang berdekatan maka mengakibatkan penyulang yang sehat ikut dialiri arus urutan nol sehingga penyulamg sehat ikut merasakan adanya gangguan di fasa yang sama maka relay GFR pada penyulang Ngurah Rai II memberikan perintah trip pada PMT, sehingga penyulang Nurah Rai I dan Ngurah Rai II padam dan keandalan penyaluran daya untuk mensuply beban bandara II tidak terjaga dengan baik 
TABEL I

DATA SETting RELAy GFR SEbELUM Di PASANGNya RELAy DGR

\begin{tabular}{|c|l|l|l|l|}
\hline \multirow{4}{*}{} & \multicolumn{2}{|c|}{ GH } & \multicolumn{2}{c|}{ GI } \\
\cline { 2 - 5 } $\begin{array}{c}\text { Ngurah Rai } \\
\text { I }\end{array}$ & GFR & $\begin{array}{l}\text { Pick up = 31 A } \\
\text { SI } \\
0.3 \text { detik }\end{array}$ & GFR & $\begin{array}{l}\text { Pick up = 34 A } \\
\text { SI } \\
0.3 \text { detik }\end{array}$ \\
\cline { 2 - 5 } & DGR & - & DGR & - \\
\hline $\begin{array}{c}\text { Ngurah Rai } \\
\text { II }\end{array}$ & GFR & $\begin{array}{l}\text { PI up =31 A } \\
\text { SI detik }\end{array}$ & GFR & $\begin{array}{l}\text { Pick up }=34 \text { A } \\
\text { SI detik }\end{array}$ \\
\cline { 2 - 5 } & DGR & - & DGR & - \\
\hline
\end{tabular}

kejadian ini disebut sympathetic trip. seperti pada gambar 4 relay GFR penyulang Ngurah Rai I dan Ngurah Rai II memberi perintah trip dan kedua penyulang manjadi padam.

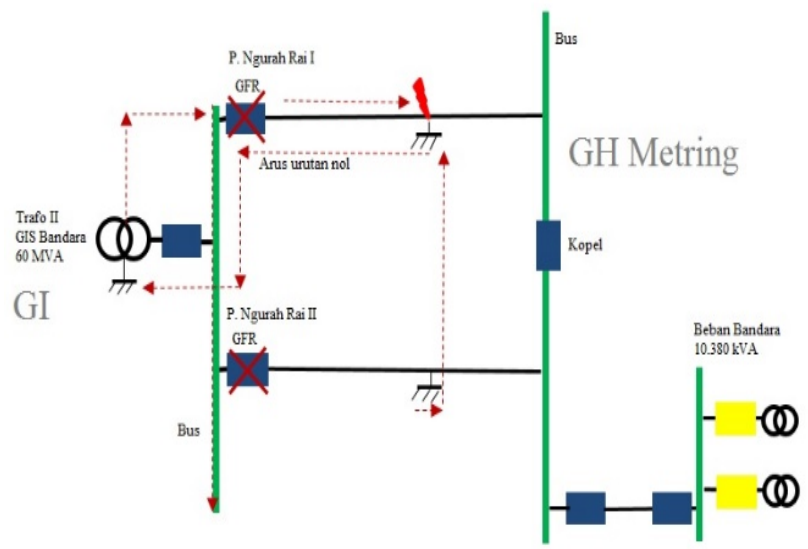

Gambar 5: Simulasi Penyulang Ngurah Rai I dan II pada saat Terjadi Sympathetic Trip

C. Impedansi Urutan Positif, Negatif dan Impedansi Urutan Nol

Bedasarkan perhitungan impedansi penyulang dengan persamaan (1) maka hasil dari perhitungan impedansi urutan positif, Negatif dan nol yang diperoleh di tunjukan pada tebel 1

TABEL II

NILAI IMPEDANSI URUTAN POSITIF DAN IMPEDANSI URUTAN NEGATIF

\begin{tabular}{|c|c|}
\hline Panjang & Impedansi Urutan Positif dan Negatif \\
\hline $0 \%$ & $0 \times(0.125+\mathrm{j} 0.097)=0+\mathrm{j} 0$ \\
\hline $100 \%$ & $4.242 \times(0.125+\mathrm{j} 0.097)=0.5302+\mathrm{j} 0.4114$ \\
\hline
\end{tabular}

TABEL III

NILAI IMPEDANSI URUTAN NOL

\begin{tabular}{|c|c|}
\hline Panjang & Impedansi Urutan nol dalam Ohm \\
\hline $0 \%$ & $0 \times(0.275+\mathrm{j} 0.029)=0+\mathrm{j} 0$ \\
\hline $100 \%$ & $4.242 \times(0.275+\mathrm{j} 0.029)=1.1665+\mathrm{j} 0.1230$ \\
\hline
\end{tabular}

D. Analisis Perhitungan Relay DGR untuk Menangani Gangguan Sympathetic trip

$I_{\text {dasar }}$ dan $Z_{\text {dasar }}$ digunakan untuk menganalisi gangguan satu fasa ke tanah pada relay DGR dihitung sebagai berikut :

$$
\begin{aligned}
I_{\text {dasar }} & =\frac{M V A_{3 \phi} \text { dasar }}{\sqrt{3} \times \text { Tegangan dasar }, k V_{L-L}} \\
& =\frac{60000}{\sqrt{3} \times 20} \\
& =1732.05 \mathrm{~A} \\
Z_{\text {dasar }} & =\frac{\left(\text { Tegangan dasar }, k V_{L-L}\right)}{M V A_{3 \phi}} \\
& =\frac{20^{2}}{60}=6.6 \Omega
\end{aligned}
$$

Impedansi netral dihitung dengan menggunakan nilai per unit sebagai berikut:

Nilai perunit $=\frac{\text { nilai asli }}{\text { nilai dasar }}$

$Z_{n}(p u)=\frac{40}{6.6}=6.06 \Omega$

$3 Z_{n}(p u)=18.18 \Omega$

\section{E. Perhitungan Arus Gangguan Hubung Singkat 1 Fasa ketanah}

Pada gangguan hubung singkat 1 fasa ke tanah tegangan $20 \mathrm{kV}$ untuk menetukan arus gangguan maka terlebih dahulu ditentukan nilai $Z_{1}, Z_{2}, Z_{0}, Z_{n}$ pada penyulang di titik lokasi $0 \%$ dihitung sebagai berikut :

Nilai Per unit $=\frac{\text { nilai asli }}{\text { nilai dasar }}$

$Z_{1}(p u), Z_{2}(p u)=\frac{0+j 0 \Omega}{6.6 \Omega}=0+j 0 \Omega$

$Z_{0}(p u)=\frac{0+j 0 \Omega}{6.6 \Omega}=0+j 0 \Omega$

$Z_{f}(p u)=0$

$Z_{n}(p u)=\frac{40}{6.6}=6.06 \Omega$

$3 Z_{n}(p u)=18.18 \Omega$

Menentukan arus gangguan hubung singkat 1 fasa ketanah $I_{a 1}(p u)$

$$
\begin{aligned}
& I_{a 1}=\frac{1}{(0.375+0+j 0 \Omega+0+j 0 \Omega+0+j 0 \Omega+18.18+0 \Omega)} \\
& I_{a 1}=\frac{1}{18.555+j 0} \\
& I_{a 1}=\frac{1}{18.5555+<0^{\circ}} \\
& I_{a 1}=0.053+<0^{\circ}
\end{aligned}
$$

Jadi arus gangguan maksimum yang mengalir dihitung sebagai berikut

I Nyoman Upanayana: Pemasangan DGR (Directional Ground Relay)...

p-ISSN:1693 - 2951; e-ISSN: 2503-2372

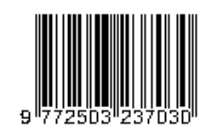




$$
\begin{aligned}
I_{f} & =I_{a 1}(p u) \\
I_{f} & =I_{f}(p u) \times I_{\text {dasar }} \\
& =0.053 \times 1732.05 \\
& =93.34 \mathrm{~A}
\end{aligned}
$$

\section{F. GPT dan ZCT pada Relay DGR}

Penyetingan tegangan tidak seimbang jika terjadi gangguan hubung singkat 1 fasa ke tanah didapatkan: $V r=34.64 \mathrm{kV}$.

ZCT pada DGR digunakan untuk mendeteksi arus gangguan hubung singkat 1 fasa ke tanah yang menimbulakan arus urutan nol. Setting ZCT dihitung sebagai berikut:

$$
\begin{aligned}
I_{\text {set }} & =10 \% \times 93.34 \\
& =9.334 \mathrm{~A}
\end{aligned}
$$

Dengan waktu trip relay

$$
t=\frac{0.14 \times 0.1}{\left(\frac{93.3454769}{8.33454769}\right)^{0,02}-1}
$$

$t=0.2970$ detik

G. Setting Relay GFR dan Hasil Perhitungan Relay DGR untuk Menanganin Gangguan Sympathetic trip

\begin{tabular}{|c|c|c|c|c|}
\hline \multirow{3}{*}{$\begin{array}{l}\text { Ngurah } \\
\text { Rai I }\end{array}$} & \multicolumn{2}{|r|}{$\mathrm{GH}$} & \multicolumn{2}{|r|}{ GI } \\
\hline & GFR & $\begin{array}{l}I_{\text {set }}==31 \mathrm{~A} \\
\text { SI } \\
0.3 \text { detik }\end{array}$ & GFR & $\begin{array}{l}I_{\text {set }}==34 \mathrm{~A} \\
\text { SI } \\
0.3 \text { detik }\end{array}$ \\
\hline & $D G R$ & $\begin{array}{l}I_{\text {set }}=9.167 \mathrm{~A} \\
0.297 \text { detik } \\
Z C T=1 \mathrm{~A} \\
G P T=34.64 \mathrm{kV}\end{array}$ & $D G R$ & $\begin{array}{l}I_{\text {set }}=9.334 \mathrm{~A} \\
0.297 \text { detik } \\
Z C T=1 \mathrm{~A} \\
G P T=34.64 \mathrm{kV}\end{array}$ \\
\hline \multirow[b]{2}{*}{$\begin{array}{l}\text { Ngurah } \\
\text { Rai II }\end{array}$} & GFR & $\begin{array}{l}I_{\text {set }}==31 \mathrm{~A} \\
\text { SI } \\
0.3 \text { detik }\end{array}$ & $G F R$ & $\begin{array}{l}I_{\text {set }}==34 \mathrm{~A} \\
\text { SI } \\
0.3 \text { detik }\end{array}$ \\
\hline & $D G R$ & $\begin{array}{l}I_{\text {set }}=9.167 \mathrm{~A} \\
0.297 \text { detik } \\
Z C T=1 \mathrm{~A} \\
G P T=34.64 \mathrm{kV} \\
\text { Reverse }=30^{\circ}\end{array}$ & $D G R$ & $\begin{array}{l}I_{\text {set }}=9.334 \mathrm{~A} \\
0.297 \text { detik } \\
Z C T=1 \mathrm{~A} \\
G P T=34.64 \mathrm{kV} \\
\text { Reverse }=30^{\circ}\end{array}$ \\
\hline
\end{tabular}

Relay GFR dan analisi perhitungan yang di dapat pada relay $D G R$ untuk menangani gangguan sympathetic trip pada penyulang Ngurah Rai I dan Ngurah Rai II.

TABEL IV

PERBANDINGAN SETting RELAy GFR DAN DGR UnTUK MENANGANi SYMPATHETIC TRIP

Dari hasil data relay $G F R$ dan perhitungan relay $D G R$ maka relay $D G R$ lebih selektif mendeteksi arus urutan nol (arus residu) yang begitu kecil 9.167 A pada GH dan 9.334 A pada GI
H. Grafik Setting Arus Relay GFR dan Arus DGR Penyulang Ngurah Rai I dan Ngurah Rai II untuk Gangguan I Fasa ketanah

Grafik hasil data setting arus GFR dan perhitngan arus $D G R$ untuk mengatasi gangguan sympathetic trip.

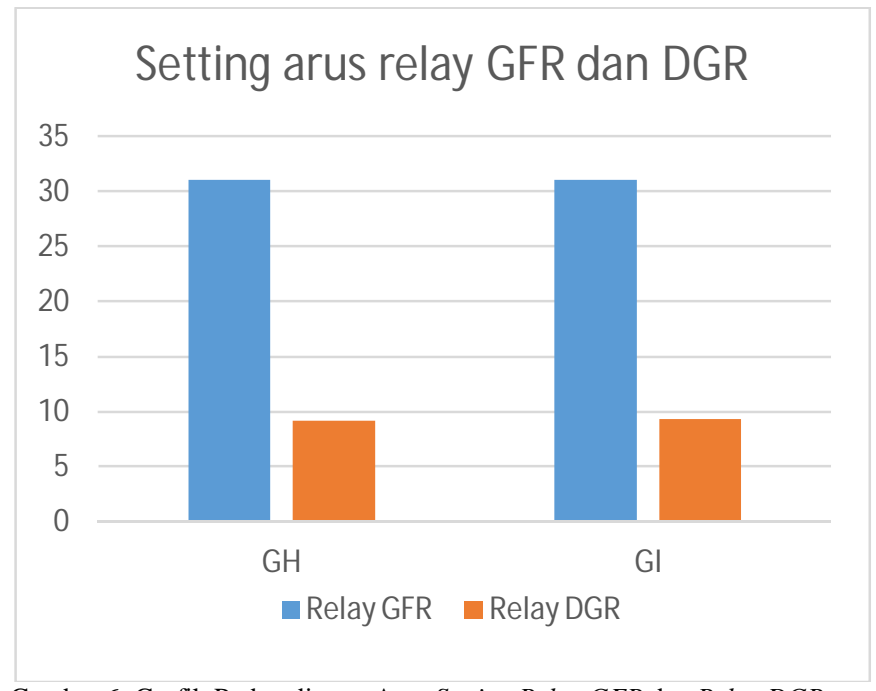

Gambar 6: Grafik Perbandingan Arus Setting Relay GFR dan Relay DGR

Dari grafik diatas diketahui arus setting gangguan pada relay $G F R$ jika adanya gangguan 1 fasa ketanah berada pada 31 A sampai 34 A jika menimbulkan arus urutan nol (arus residu) yang nilai arusnya begitu kecil dan tidak dapat dideteksi oleh relay GFR.

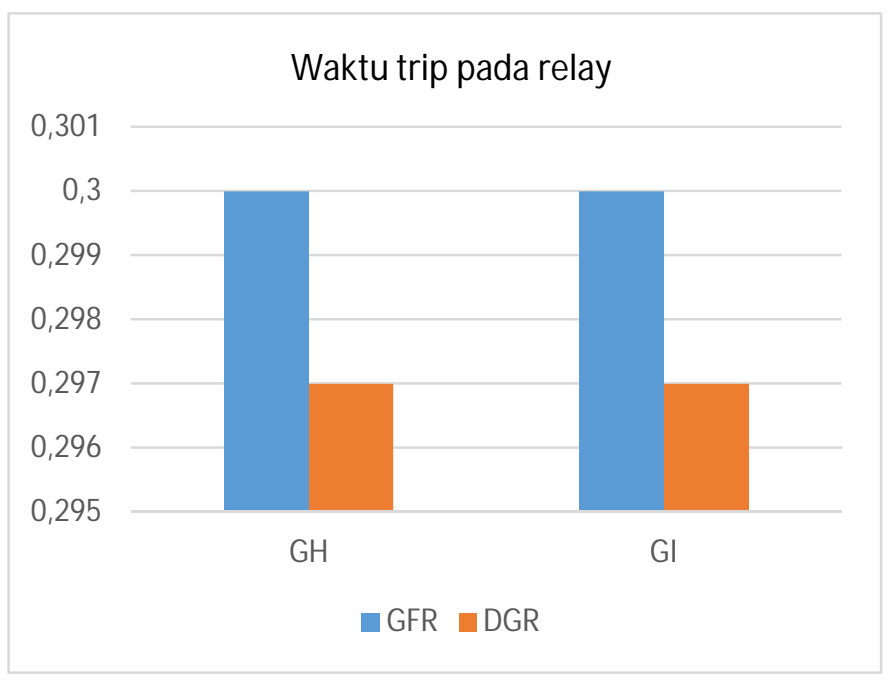

Gambar 7: Grafik Perbandingan Waktu Trip Relay GFR dan Relay DGR

Pada gambar 7 grafik perbandingan waktu perintah trip dari relay DGR 0.297 dari Relay GFR 0.3 lebih cepat jika gangguan 1 fasa ketanah menimbulkan arus urutan nol.

\section{Simulasi Relay Directional Perogram ETAP}

Analisis perhitungan yang setting relay DGR jika terjadinya gangguan 1 fasa ketanah yang dapat menimbulkan 
gangguan sympathetic trip disimulasikan seperti pada gambar 8

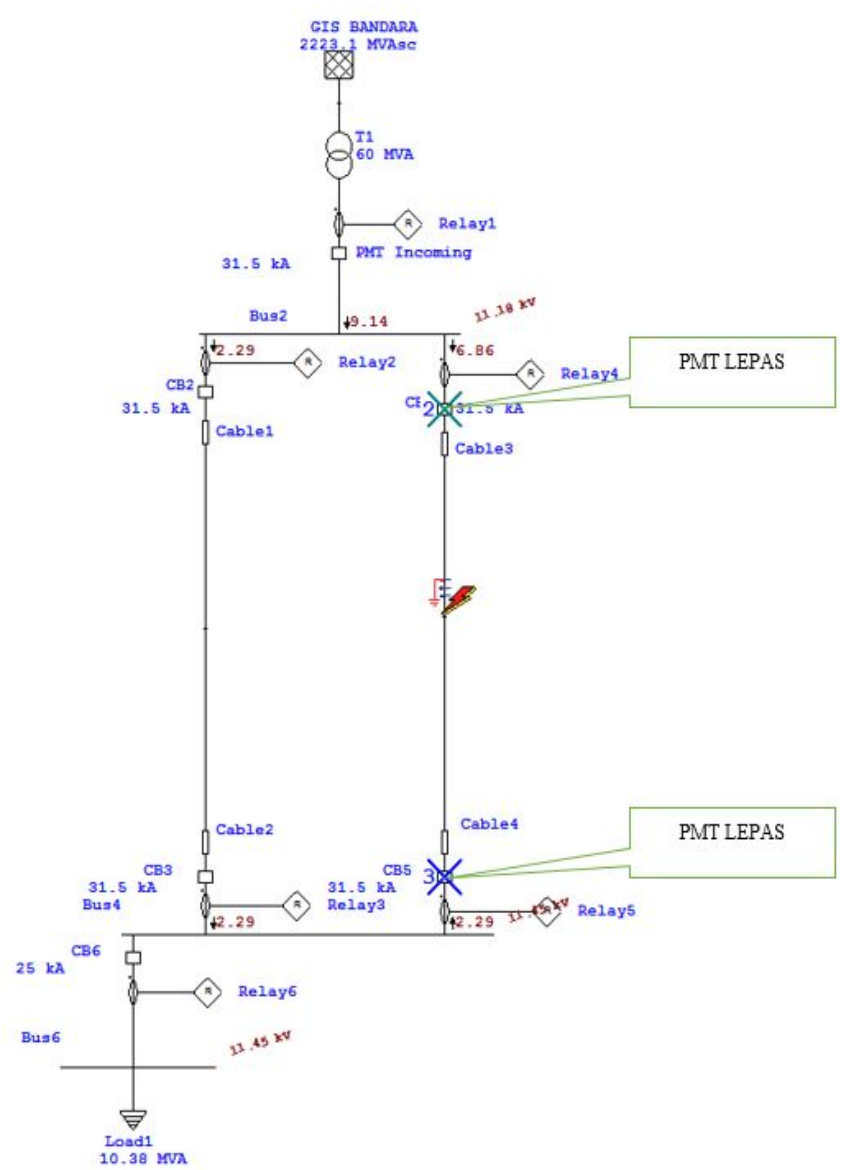

Gambar 8: Hasil Simulasi Relay DGR Penyulang Ngurah Rai I dan Ngurah Rai II

Hasil simulasi gambar 6 pemasangan relay $D G R$ (Directional Ground Relay) pada penyulang Ngurah Rai I dan Ngurah Rai II sangat epektif, jika terjadi gangguan hubung singkat 1 fasa ke tanah maka kordinasi relay GFR dan $D G R$ akan memberi perintah trip ke PMT dengan waktu hapir secara bersamaan dan sympatthetic trip tidak terjadi pada penyulang Ngurah Rai II, karena relay $D G R$ sudah terlebih dahulu memblok arus urutan nol yang dideteksi oleh ZCT dan tegangan urutan nol dideteksi oleh GPT.

\section{KESIMPULAN}

Setting relay GFR pada penyulang Ngurah Rai I dan Ngurah Rai II sebelum di pasangnya relay $D G R$, dengan setting arus pada GH 31 A, pada GI 34 A, standart inverse dan waktu trip 0.3 detik, jika terjadi gangguan 1 fasa ketanah yang dapat menimbulkan arus urutan nol dan menyebabkan terjadinya gangguan sympathetic trip pada penyulang Ngurah Rai I dan Ngurah Rai II sehingga beban Bandara II padam.

Pemasangan relay DGR untuk mengatasi gangguan sympathetic trip pada penyulang Ngurah Rai I dan Ngurah Rai II berdasarkan perhitungan diperoleh setting DGR sebesar, setting arus pada GH 9.167 A, pada GI 9.334 A, waktu trip 0.297detik, ZCT 1 A dan GPT $34.24 \mathrm{kV}$ yang di kordinasikan dengan relay GFR maka jika terjadinya gangguan 1 fasa ketanah yang menimbulkan arus urutan nol yang dapat menyebabkan terjadinya sympathetic trip pada penyulang tidak dapat kembali kesumber karena adanya relay DGR yang memblok arus urutan nol dan sistem keandalan penyulang ngurah rai I dan Ngurah Rai II untuk beban bandara II tetap terjaga.

\section{REFERENSI}

[1] Ikhwan, M. 2011. Studi Rele Pengaman Standby Genset di PT. CocaCola Bottling Indonesia Belawan-Medan (Karya Akhir). Medan : Universitas Sumatera Utara.

[2] Darwanto, Agus \& Priyanto, Joni, 2012. Studi Penggunaan Directional Ground Relay (Dgr) Tipe EGR-EC Sebagai Pengaman Gangguan Fasa Tanah Penyulang 20 KV Thamrin Di PT. Pln APJ Bojonegoro, Jurnal Jurusan Teknik Elektro STTR Cepu. No 15.

[3] Setiadji, J.S, Machmudsyah T. \& Kongdoro R. (2006). Analisis Gangguan Satu Fasa ke Tanah yang Mengaibatkan Sympathetic Trip pada Penyulang Yang tidak Terganggu di PLN APJ Surabaya Selatan. Jurnal Universits Kristen Petra, Vol 6, No.1

[4] 2010. PT PLN (Persero). Kriteria Disain Enjinering Konstruksi Jaringan Distribusi Tegangan Listrik. Jakarta Selatan.

[5] Sutarjana, I. K, Arjana I. G. D, dan Partha, T. G. I. 2015. Studi Analisis Setting Relay Pengaman di Penyulang Ngurah Rai I dan Ngurah Rai II. Jurnal Teknik Universitas Udayana, Vol 2, Nol 1.

[6] Sarimun, W.N. 2012. Proteksi Sistem Distribusi Tenaga Listrik. Edisi Pertama. Kota Depok, Penerbit: Garamod. 